\title{
La representación de la moda en tres novelas de Carmen Martín Gaite
}

\author{
GiUlia TOSOLINI \\ Università degli Studi di Udine
}

Resumen: El artículo pretende ofrecer una nueva y contemporánea lectura de la obra de Carmen Martín Gaite a través del análisis de tres novelas ( $E l$ cuarto de atrás, Nubosidad variable, Irse de casa) en el ámbito de los estudios culturales y, en particular, de la Fashion Theory, que se ocupa de la relación de la moda con otras expresiones culturales, en este caso la literatura. La moda como fenómeno social, como sistema lingüístico no verbal y como elemento cultural entra en el estudio de las obras, en las que, con sus extensiones, desempeña distintas funciones, útiles a la caracterización de los personajes, a la creación de los ambientes, y, gracias al abundante simbolismo, a la representación metafórica.

Palabras clave: estudios culturales, moda, literatura femenina, Carmen Martín Gaite

\section{The representation of fashion in three of Carmen Martín Gaite's novels}

Abstract: The article aims to produce a new contemporary reading of Carmen Martín Gaite's work through the analysis of three novels (El cuarto de atrás, Nubosidad variable, Irse de casa) from the perspective of the Cultural Studies' branch of Fashion Theory, which offers an interpretation of the connection between fashion and other cultural phenomena, in this case literature. Fashion as social event, as non-verbal linguistic system and cultural aspect is involved in the literary criticism of the books, in which it plays different functions, useful to the character's definition, the description of the places and, thanks to its important symbolism, the metaphorical representation.

Key words: Cultural Studies, Fashion, Female Literature, Carmen Martín Gaite 


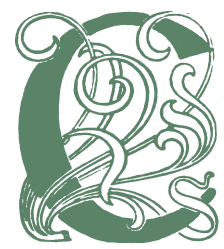

asi un siglo después de la publicación de Orlando (1928), en el que Virginia Woolf declaraba que los trajes desempeñan «more important offices than merely to keep us warm. They change our view of the world and the world's view of us» (Woolf, 1992: 179), en el artículo Off the page: fashion in literature editado en The Guardian el 19 de septiembre de 2009, la periodista Helen Gordon invita a los lectores a inspirarse en la literatura para escoger la ropa para llevar. En la columna, testimonio de la amplia difusión alcanzada hoy en día por el tema, Gordon acerca la moda y la literatura como similares «arts of expression and craft» (Gordon, 2009), y evalúa el poder de un traje por su función intelectual, o sea por el mensaje transmitido o la reacción provocada.

No obstante una aparente distancia que separa estos dos aspectos culturales, la relación entre ellos es un fenómeno contemporáneo patente y productivo, que entra de derecho en los estudios académicos. Muchas disciplinas científicas -sociología, antropología, psicología, semiología- han mostrado su interés por el tema de la moda, que desde hace algunas décadas ensalza un propio ramo en los Estudios Culturales, la llamada Fahsion Theory ${ }^{1}$. De origen anglosajón, esta disciplina -todavía poco difundida en la Europa mediterránea- analiza la moda en sentido multidisciplinar y abierto a todas las perspectivas, centrándose en la relación entre cultura, moda y traje, con un método que funde las ciencias sociales, la historia de la costumbre y la historia del arte en clave posmoderna, considerando los discursos sociales como lugares en los que la moda se realiza. El traje, a lo largo de la historia, ha desempeñado un papel esencial en la construcción de la identidad colectiva e individual y en el ámbito del mismo sistema al que pertence. Se puede concebir como la base comunicativa proporcionada por el lenguaje de la

1 En el Dizionario degli Studi Culturali de Michele Cometa, Patrizia Calefato define así el fenómeno: «Fashion theory indica un ambito interdisciplinare che concepisce la moda come un sistema di senso entro cui si producono le raffigurazioni culturali ed estetiche del corpo rivestito. [...] [con] un approccio teorico trasversale [...]» (http://www.studiculturali.it/dizionario/lemmi/fashion_theory.html, consultado el 20/01/2017). Algunas referencias bibliográficas básicas sobre el tema son: el ensayo de Lipovetsky, Gilles (1987) que rescata la moda y su valor social; el ensayo sobre la definición del concepto 'moda' y el estudio de la relación entre haute couture y moda común de Craik, Jennifer (1993); el estudio diacrónico del fenómeno y de su simbología por Lurie, Alison (1994); el análisis de la moda como elemento de definición social y de género en Crane, Diana (2000); las actas a cargo de Montoya Ramírez, María Isabel (ed.) (2001), que reúnen contribuciones sobre la relación entre arte, moda, lenguaje y literatura; Guy, Ali; Green, Eileen; Banim, Maura (eds.) (2003) para un enfoque femenino de los Fashion Studies; Kawamura, Yuniya (2005), base teórica para la definición de la Fashion Theory y de sus orientaciones. 
moda, con una estructura que lo acerca a la escritura o al lenguaje verbal, y se caracteriza por ser específico, visivo y no verbal, semi-arbitrario -o sea vinculado a las leyes del cuerpo- e inteligibile -útil por el sentido que vehicula más que por su esencia de objeto-, como subraya Roland Barthes, iniciador del proceso que ha acercado este aspecto cultural a los estudios científicos ${ }^{2}$. A lo largo del siglo XX también Ferdinande De Saussure, Pëtr Bogatyrëv, Nikolaj Trubeckoj e Jurij Lotman ${ }^{3}$ habían propuesto distintas lecturas del valor semiótico del traje. Fue Umberto Eco quien amplió su valor social, interpretando el de la indumentaria como un lenguaje cultural visivo articulado. Según el semiólogo italiano los trajes, perdiendo el papel primario y concreto de cubrir un cuerpo desnudo, pueden vehicular un mensaje, muy a menudo relacionado con el aspecto emotivo que une el traje al cuerpo, pilar del sistema cultural contemporáneo (Eco, 1972). Estas son algunas de las bases teóricas que la crítica literaria europea considera para investigar la relación entre moda y literatura, con distintos rumbos: los aspectos de la moda literaria, la interacción del fenómeno con la literatura nacional o con un autor en particular, la comparación del tratamiento en las literaturas europeas, etc.

El siglo XX, que ha visto la afirmación de la moda como fenómeno social colectivo y evolutivo, la hegemonía de la imagen en la percepción del indviduo y de la cultura, en España, se ha caracterizado por hitos cruciales en la determinación de esta percepción, que van de la dictadura franquista a los fenómenos artísticos y culturales de los años de la transición democrática.

Carmen Martín Gaite es una de las voces femeninas más relevantes del panorama literario del siglo XX español. Su figura siempre ha interesado a los estudiosos de todo el mundo y la producción crítica acerca de su vida y obra es copiosa. Con estas premisas, el objetivo del artículo es proporcionar un punto de vista nuevo y actual para interpretar su trayectoria literaria, analizando la función de la moda en tres obras: El cuarto de atrás (1978), Nubosidad variable (1992) e Irse de casa (1998), elegidas por la relevancia del tema tratado. La moda y sus extensiones ofrecen una nueva interpretación de te-

2 En el ensayo Système de la mode (1967) Barthes, fundador de los estudios semióticos sobre la moda, elabora el pasaje a una teorización de ésta como discurso social. Sobre la comparación de la moda como sistema lingüístico la referencia principal es Nikolaj Trubeckoj, que retomando el esquema saussuriano, identifica la langue con las costumbres y la parole con el vestuario.

3 Los textos a los que se hace referencia son respectivamente Curso de lingüística general (1916), Las funciones del traje popular en la Eslovaquia morava (1937), Principios de fonología (1939) y Cultura y explosión (1993). 
mas y constantes del mundo gaitiano, fortaleciendo y confirmando el poder creador de la escritora salmantina, pero desde una perspectiva muy contemporánea. De hecho, las contaminaciones entre moda y literatura -mundos muy distantes, pero que en realidad albergan muchos elementos en común, a partir del trabajo artesanal y delicado que tanto el modista como el escritor realizan- en la obra de Martín Gaite confirman la riqueza de la relación.

A este respecto muy sugestiva es la consideración de Encinar y Glenn que refiriéndose a Amparo Miranda, protagonista de Irse de casa, detectan en su personaje un punto de contacto entre la creación sartorial y la escritura: Amparo «es una diseñadora de moda que fabrica prendas a la vez que construye un yo, y la fabricación -en el doble sentido de crear una cosa e inventar mentiras o historias- es uno de los rasgos de la escritura del yo» (Encinar y Glenn, 2014: 96), que sabemos típica del universo femenino, al que Martín Gaite dedica enteramente su obra. En esta novela de la madurez, la última publicada en vida, la moda tiene quizás su mayor visibilidad; los trajes y complementos concretan aquí una condición, construyen la imagen de los personajes y al mismo tiempo adquieren cierto grado de intimidad y profundidad no detectable en otras obras; son, en efecto, metáfora de la creación, del trabajo puntual y preciso de cada artista, que realiza su obra yuxtaponiendo elementos diferentes, armonizándolos y al mismo tiempo manteniendo las varias individualidades:

Toda creación consiste en lo mismo, en saber coser los elementos dispersos, y entender cómo se relacionan entre sí, da igual que sean historias o pedazos de tela, en el fondo es cuestión de quitar y poner, de prescindir a veces de lo que desentona, pero no siempre, tampoco vienen mal las estridencias en alguna ocasión (Martín Gaite, 1998: 320).

Para acercarnos al análisis de las obras cabe, ante todo, tener en cuenta la relación que la misma Martín Gaite tuvo con la moda. La costura, es una actividad a la que Carmen, como todas las mujeres de su generación criadas en el Servicio Social, se dedica a menudo. En el recuerdo de uno de sus entrañables amigos, la imagen de Calila cosiendo es

Sedante y brillante [...]. [...] un espectáculo de silenciosa, infinita belleza. Como una salida o una puesta de sol en la terraza de Doctor Esquerdo. Ella cosía con un primor insuperable. Y al verla se entraba sin saberlo en el taller de las hadas (Álvarez Vara, 2005: 126). 
Son también los escritos más íntimos ${ }^{4}$ que revelan como la imagen de la escritora está totalmente desvinculada de los clichés y de las imposiciones de la sociedad, como su escritura. En el Cuaderno de todo número dos se lee: «con un traje viejo se tiene más personalidad desde el punto de vista de que es la persona la que lo habita, no ella la habitada, la uniformada» (Martín Gaite, 2003: 95). De esa forma se subraya la necesidad de crear un estilo propio para fugarse de la homologación, puesto que la manera de vestir representa un elemento constitutivo de la imagen. De hecho, vuelve aquí la voz inspiradora de Virigina Woolf: la influencia del vestuario sobre las protagonistas de las novelas analizadas es muy evidente; como señala también Helen Gordon, la identidad de las mujeres «has tipically been more closely linked to their outer appereance than that of their male counterparts» (Gordon, 2009).

En la inagotable fuente de motivos e ideas representada por los Cuadernos de todo, además de un encuentro fortuito con una posible Lady Drake ${ }^{5}$, se registran de vez en cuando curiosos detalles sobre el vestuario como pinceladas impresionistas: breves descripciones que confirman como la moda puede considerarse un hábito femenino, acompañado por cierta vanidad, y que demuestran la capacidad de Carmen Martín Gaite de convertir un recuerdo vestimentario en un menester literario. Es cierto que el interés de la autora salmantina por la moda está asociado también a su actividad de escritora e historiadora, que la llevó a sondear el terreno de las costumbres vestimentarias de los siglos XVIII y XX ${ }^{6}$, cuya influencia se aprecia también en su ficción. El mundo literario de Carmen Martín Gaite está poblado de tipos femeninos muy diversos y distantes entre ellos, que comparten la tarea de defender un papel social a la vez que la propia conciencia pesonal. Es precisamente siguiendo estas dos vertientes que el fenómeno de la moda se configura como social y personal, universal e individual al mismo tiempo. En la trayectoria literaria gaitiana la crítica social de las primeras décadas

\footnotetext{
4 Cf. Bosquejo autobiográfico (1993), Cuadernos de todo (2002), Visión de Nueva York (2005).

5 El personaje de Amparo Miranda, Drake de casada, puede ser el resultado del encuentro que la autora registra así: «Ahora (3 de octubre), vengo por Madison Av. de la librería Hispánica, donde he dejado una de las fotos grandes de Pablo Sorozábal, vengo en uno de los autobuses nuevos, sentada junto a una mujer muy elegante con pinta de millonaria neoyorkina. Tiene el pelo blanco, falda de pied-de-poule gris, blusa blanca y una chaqueta negra de punto. También joyas y un paraguas precioso. Mira con sus ojos claros segura de que todos se sienten atraídos por ella, por su resplandor. Debe tener unos sesenta» (Martín Gaite, 2003: 639).

6 Cf. los ensayos de Martín Gaite Usos amorosos del XVIII en España (1972) y Usos amorosos de la posguerra española (1987).
} 
se amolda para dar paso a una intensa actividad de investigación que luego deja paso otra vez a la ficción, más intimista y psicológica. Así es también la evolución que el tema de la moda sufre en las novelas consideradas: de testimonio histórico-cultural (El cuarto de atrás) pasa a ser un elemento individual (Nubosidad variable), y al final se convierte en una máscara del yo, en una metáfora de los avatares emotivos (Irse de casa). A este respecto, el estudio ha individuado por lo menos cinco principales funciones de la moda, que se configura como metáfora del quehacer literario; como instrumento para la creación de personajes y ambientaciones, tanto a nivel concreto como simbólico; como motor del recuerdo, profundamente vinculada a la memoria, tema muy frecuentado por la autora salmantina; como testimonio, con un importante valor histórico-cultural; y como máscara.

El valor metafórico de la moda aparece en Martín Gaite asociado sobre todo al quehacer literario y a la escritura ${ }^{7}$ : la cesta de la costura de El cuarto de atrás y el cuarto o cuartito de costura que aparecen en Nubosidad variable e Irse de casa son auténticas representaciones del trabajo creativo que acerca la realización del vestido a la escritura. Para nuestra autora la isotopía de los utensilios del sastre en desorden en la cesta refleja el caos que antecede a cualquier creación artesanal o manual y las posibilidades creativas presentes y futuras. La imagen de la cesta de la abuela Rosario y del mundo que guarda en su interior en El cuarto de atrás es un claro ejemplo de esta función literaria desempeñada por la costura, y, según López Rodríguez (2011), también una imagen de fusión entre modernidad y tradición:

Casi no cierra de puro llena, no puedo comprender cómo caben dentro tantas cosas; siempre acudo a ella en casos de perplejidad, aquí acaba viniendo a parar todo, seguro que, al abrirla, me acordaré de lo que venía a buscar. [...] De la tapadera de mimbre entreabierta escapan carretes, enchufes, terrones de azúcar, dedales, imperdibles, facturas, un cabo de vela, clichés de fotos, botones, monedas, tubos de medicinas, allá va todo, envuelto en hilos de colores (Martín Gaite, 1997: 19).

\footnotetext{
7 Tanto la metáfora de la costura y del hilo como el recurso a términos relacionados con este ámbito semántico para referirse al mundo de los libros y del discurso lingüístico se hallan, por ejemplo, en Las ataduras (1959) y en Retahílas (1974). Cf. López Alonso, Covadonga (2004). También Maria Vittoria Calvi señala como en la escritura de Martín Gaite «la identidad narrativa se concibe [...] como la acción de coser, que expresa la urdimbre de un relato que se crea de forma dinámica y abierta, sin miedo a "perder el hilo", oponiéndose a la acción de atar, que alude a una contrucción artificiosa y autocomplaciente» (2014: 126).
} 
La misma variedad caótica, sinónimo de un ánimo creativo y apasionado, se encuentra en la cesta descrita en Nubosidad variable:

- ¡Tendrás cara de exigirme un antes y un después, mamá, con todos estos cachitos por el aire y por el suelo! Retales más bien, ¿no te parece?, hilos, botones, imperdibles y carretes vacíos, «trampantojos de costura», como diría la yaya, porque todo es coser (Martín Gaite, 2010: 405).

La importancia metaliteraria de la escritura en la vida y la obra de la autora -y de reflejo en la de sus personajes- es consabida, como también su afición a las metáforas ${ }^{8}$. Tanto por la escritura como para la realización sartorial, que «se convierte en metáfora de un proceso de creación de identidad femenina» (López Rodríguez, 2011: 175), el compromiso con la elaboración de un trabajo creativo que va ampliándose poco a poco con la experiencia está vinculada a la particular predisposición de las mujeres en este sentido ${ }^{9}$. Efectivamente, en el mundo gaitiano la creación y su poder están fuertemente enlazados con el mundo femenino, tanto como los espacios domésticos, concreción de esa dimensión emotiva, ese Room of one's own (1929) de woolfiana memoria. El cuartito de la costura, así como el más famoso cuarto de atrás, son lugares esenciales tanto para el desarrollo de la trama novelesca como para la evolución de los personajes. La función psicológica y emotiva de la habitación protagonista de la novela de 1978 es la misma que la del cuarto de costura en Irse de casa, donde la afirmada modista Amparo Miranda encuentra la inspiración para realizar sus creaciones. La intimidad de este último refugio auténtico choca con la frenética cotidianidad que la protagonista vive, guardando una esencia casi mágica:

En contraste con la estricta simetría de rombos y mármoles a que obedecían las demás estancias de aquel apartamento amplio y elegante donde ningún objeto desentonaba, el desorden y la aglomeración del cuartito lo convertían en recodo clandestino de subversión, en escondite y nido. No en vano aquella puerta negra con pomo de cristal se cerraba siempre que había un "party" o una reunión de trabajo, era ley aprendida de antiguo, y cuando mamá mandaba cerrar la puerta del cuartito para que no salieran ruidos ni olores de allí, estaba también cerrando la de su propia alma (Martín Gaite, 1998: 23).

8 Cf. Contadini, Luigi (2000); Escartín Gual, Montserrat (2001; 2014); Jurado Morales, José (2003); Freixas, Laura (2006); Medina, Hector (2009); Miranda, Karen (2009).

9 Cf. Agosín, Marjorie (1993) sobre el tema de la mujer creadora, hacedora, artesana de la palabra. 
Para Sofía, protagonista de Nubosidad variable, el cuarto de costura despierta su memoria, aludiendo al pasado y a la figura de su madre, tanto en sus sueños como en su proyecto literario, del que se habla en el capítulo Persistencia de la memoria, donde tropezamos con el elemento metaliterario típico de la escritura gaitiana, que tanto para Carmen como para sus protagonistas es «una escritura "diferente" [...] ejercicio de autodescubrimiento sin la necesidad de una autorización patriarcal» (Zecchi, 2006: 529):

Reconozco, aunque está muy cambiado, mi cuarto de costura. El armario de luna de tres cuerpos, por ejemplo, ha desaparecido como por arte de magia [...]. Me había dormido vestida, como aquella noche lluviosa de spetiembre en la butaca de mamá. [...] [Mamá] Mandó que no la movieran del cuarto de costura, había insistido mucho en aquello, según contó Adela, que la dejaran aquí, que tiene que ser donde a uno le pille la suerte, que a su abuela Carmen también la había pillado cosiendo, [...]. De manera que allí se la puso, en el cuarto de costura, que era éste, he tardado en darme cuenta, parecía más grande con los tres espejos del armario de luna. [...] No había vuelto a entrar en este cuarto ni sé por qué estoy en él ahora. Y me quedo absorta, con los ojos fijos en el centro de la estancia, donde se instaló el rectángulo negro rodeado de hachones, y ella acostada dentro, sobre un fondo de raso malva. La miraba desde mi butaca, mejor dicho, la suya, no directamente, sino reflejadas ella y yo en las tres lunas del armario ropero, que cogía casi toda la pared de enfrente (Martín Gaite, 2010: 373; 379; 383).

Estos lugares plasman auténticas alternativas al mundo real, encarnan puntos de contacto con el universo interior y umbrales para un diálogo con el propio yo. Son, en fin, espacios de evasión interior.

El traje destaca evidentemente también por su tarea descriptiva a la hora de caracterizar a personajes y ambientes, también por su significado simbólico. El vestido se puede considerar metonimia de quien lo lleva, como símbolo de una condición; como apunta Martinell Gifre «en todas las obras hay una clara conciencia del nivel social, la situación, y la personalidad atribuidos a cada personaje y el tipo de ropa con el que se le vesitrá» $(1996,54)$. A parte de la evidente conexión entre vestuario y status social, edad o empleo, el traje revela aspectos psicológicos y figurados. Por ejemplo, el hombre de negro que visita a C. en El cuarto de atrás, por su atuendo monocromático representa la kafquiana dimensión psíquica y se puede considerar como antropomorfización del inconsciente de la protagonista: 
[...] se para y un hombre vestido de negro sale y se queda mirándome de frente. Es alto y trae la cabeza cubierta con un sombrero de grandes alas, negro también. [...] Y me tiende una mano grande y delgada, un poco fría. [...] Tiene el pelo muy negro, un poco largo; sus ojos son también muy negros y brillan como dos cucarachas (Martín Gaite, 1997: 29-30).

Widmann (1999), en su ensayo sobre la simbología del color, individúa en el negro el vacío que anticipa la creación, un estado psíquico que precede la conciencia, la separación de una condición que conduce a otro nivel; y efectivamente la novela es la elaboración del recuerdo metaliterario de su propia redacción.

En la novela epistolar de 1992 la indumentaria identifica a los personajes, a menudo definidos por lo que llevan: es el caso de una «señora con chaleco de lentejuelas» (Martín Gaite, 2010: 82); de Silvia, que «traía un vestido amarillo» (139) o de Soledad, descrita «con unos pantalones negros de pana» (168); y también de la «niña de nueve años con un vestido de color celeste» (162), o de la foto de Guillermo «en que está de medio perfil, con un jersey de cuello alto» (165). Los trajes representan aquí a la sociedad posmoderna tout court, ampliando el contraste que se produce entre esta última y las dos protagonistas, que quedan muy alejadas de todo lo que es apariencia y ostentación. A este respecto, la neurosis de las ropas, estudiada por la psicóloga Mariana, es espejo de la cultura posmoderna, de su frenesí y vacuidad. Como su amiga, Sofía también es muy lejana de los estereotipos, y con su estilo peculiar, muy personal de pordiosera ${ }^{10}$, criticado por el marido -indiscutido icono del Madrid acomodado y efigie posmoderna-, defiende y afirma su personalidad. También en Irse de casa los protagonistas se nos presentan por lo que llevan, calificando de ese modo a la joven rebelde, a la chica de aspecto cuidado o a la mujer de luto. ${ }^{11}$

\footnotetext{
10 Epíteto utilizado por el mismo marido Eduardo cuando los dos eran jóvenes y que identifica el estilo y la actitud independiente y no homologada de Sofía, que entonces el marido apreciaba: «A él entonces le gustaba que yo no me maquillara, le gustaba mi disponibilidad inmediata, mi forma de vestirme, de moverme y de dar una opinión contra corriente, me decía que era gitana y que no se me ocurriera nunca convertirme en paya [...]. O sea que "ir de pordiosera" llegó a desembocar en una especie de piropo; io era "la pordio", y me encantaba serlo» (Martín Gaite, 2010: 19).

11 Por ejemplo: «Llevaba una boina de pelé por la que asomaban dos trencitas, cazadora vaquera con muchos pins y minifalda. Calzaba botas cortas de tipo militar» (Martín Gaite, 1998: 11); «[...] llevaba un corte de pelo de peluquería buena y conjunto de pantalón y camiseta de marca, aunque aparentemente informal, jersey color salmón anudado al cuello, pulsera de marfil ajustada por debajo del codo, uñas de porcelana» (Martín Gaite, 1998: 173); «eligió unas medias negras muy finas que sólo se había puesto un
} 
Como ya señalado los trajes están relacionados con la memoria, como evocadores del recuerdo de una cara, de una mirada, de un pensamiento, de una experiencia. En Martín Gaite, la memoria histórica se cruza con la memoria intrahistórica de los personajes, mezclando hitos fundamentales de la historia del país con los problemas de toda la vida. Sobre todo en la novela de 1978, pero de manera más sutil también en las otras, se realza el valor de la moda como factor histórico, testigo de una evolución o, mejor dicho, de una involución de las costumbres durante la posguerra, como evidencia también López Rodríguez (2011). Por eso, los ya citados ensayos de costumbres son documentos esenciales para analizar la obra ficcional gaitiana. En Usos amorosos de la postguerra española, por ejemplo, aparecen capítulos dedicados a los modelos femeninos aceptados o no por el régimen franquista, que, como en cualquier otro campo socio-cultural, censuraba posibles señales de renovación, también por lo que atañe a las costumbres y a la moda femenina. Hasta la muerte del Generalísimo y en concreto hasta su entierro, cuyas secuencias reviven magistralmente en El cuarto de atrás, para Martín Gaite y la mayoría de los españoles el tiempo parece paralizado, y con él todos los ámbitos de la vida. El «proceso de embrutecimiento sistemático de la mujer inventado durante la dictadura» (Ciplijauskaité, 2000: 23), cuyo modelo eran las mujeres abnegadas y laboriosas, pasa también por los dictámenes sobre el vestuario, «ligado al sentir del pueblo español» (López Rodríguez, 2011: 172), -otro canal útil para el control de las conciencias y la represión de la libertad personal- causando cierta dificultad en expresar y vivir su propia feminidad, también por parte de la misma chica rara. En efecto la apariencia y la manera de vestir eran símbolos o síntomas de cierta españolidad, de aquel «modelo de mujer acorde con la ideología franquista, es decir, cristiana, pasiva, sumisa, abnegada ama de casa, madre y esposa» (López Rodríguez, 2011: 173) que estaba en las antípodas con respecto a los modelos estadounidenses de la niña topolino o swing proporcionados por las películas de Hollywood y claramente obstaculizados por el régimen de Franco. En la novela de 1978, Martín Gaite comenta, a lo largo de la onírica entrevista con el hombre de negro, líricos recuerdos de un pasado autobiográfico también vinculados al Servicio Social frecuentado «a regañadientes» (Martín Gaite, 1997: 512), a peinados $\mathrm{y}$ atelier, a modistas y costureras, a excursiones a Madrid para renovar el

par de veces [...]. [...] vestida de luto riguroso y con los ojos llenos de lágrimas. Llevaba un bolso negro imitación cocodrilo que casi nunca usaba [...]» (Martín Gaite, 1998: 265). 
guardarropa de la familia, perdida entre «frunces, nesgas, bieses, volantes, pinzas y nidos de abeja» (Martín Gaite, 1997: 71), sumándose a las otras plumas femeninas, que «attraverso la moda raccontano i momenti decisivi della questione femminile, esprimendo in maniera apparentemente leggera e disimpegnata una vera e propria mutazione antropologica» (Baroncini, 2010: 112), siempre lejos del feminismo más político, en favor de una literatura que funde las historias comunes a la Historia institucional y también la ficción con la realidad.

Al lado de la memoria histórica es también la individual la que va a ser solicitada, como en el caso del vestido rojo protagonista del capítulo XIII de Nubosidad variable, testimonio del poder evocador del traje que llega a ser el lugar-depósito de los sueños más íntimos de una joven Sofía. La detallada y apasionada descripción de la prenda revela la gran importancia que la misma tuvo en aquel particular momento de la vida de la protagonista:

Era exactamente de mi talla y se me adaptaba al cuerpo como un guante. En cuanto a la resurrección y la quema de fantasmas, siendo como eran augurios bastante en consonancia con los formulados por las hadas de los cuentos, tengo que confesar que me quedé un rato largo contemplándome delante del espejo, al acecho de algún prodigio. Y la muchacha de rojo se desprendió de mí como una desconocida, a medida que se acentuaba la sonrisa sensual con que parecía invitarme a un peligroso juego de complicidades. [...] El escote era cuadrado y bastante generoso, con dos clips. Desde luego no era mi estilo de vestir ni de moverme, pero me encontraba guapísima. Pensándolo bien, la mayor transformación consistía precisamente en aquella complacencia al descubrirme distinta y gustarme. Creo que nunca me he mirado tanto rato seguido al espejo, era como una situación hipnótica. (Martín Gaite, 2010: 249)

El fuego que ese traje rojo, regalo de su hada-madrina ${ }^{12}$ y que venía de París -reino de la haute-couture-, despierta en la muchacha es el mismo fuego que Guillermo intenta encender en la casa de la fiesta donde los dos se van a encontrar esa misma noche ${ }^{13}$. Ambos metáforas del fuego de la pasión juvenil impetuosa que los dos vivirán.

\footnotetext{
12 La cartita que acompaña al regalo dice: «No sé si es de tu talla. Pero el fuego no tiene tallas. Espero que en esa hoguera ardan todos tus fantasmas y resucite tu cuerpo» (Martín Gaite, 2010: 249).

13 «[...] lo primero que estalla es el color rojo en mitad de todos los demás, y mi cuerpo resucitando dentro de esta funda de fuego, mientras sigo con la mirada una silueta, nimbada también de resplandores rojos, en cuclillas ante llamas de cierta chimenea, tratando de avivar las brasas con un fuelle» (Martín Gaite, 2010: 243).
} 
A la hora de establecer el potencial comunicativo de la moda el color juega un papel fundamental. En este caso el rojo -para Artemidoro símbolo de suerte, en la simbología eclesiástica sinónimo de pasión y fe, en las creencias populares emblema ambiguo del amor, del fuego, de la vida y, al mismo tiempo, del infierno-,que se contrapone al color gaitiano por excelencia, el azul -color del alma, de la reflexión introspectiva, de la intución y de la creatividad-, es un elemento de conexión con el mundo de los cuentos, al que pertenece también la figura de la hada-madrina. La naturaleza mágica de un complemento rojo remite a Las zapatillas rojas (1845) andersenianas y a la película $\mathrm{El}$ Mago de $\mathrm{Oz}$, adaptación de la novela El maravilloso mago de $\mathrm{Oz}$ (1900) de Frank Baum ${ }^{14}$. Del mismo modo el vestido se convierte en talismán también para la otra protagonista, Mariana: «el traje sastre de gabardina, que ya tiene sus años y no lo intenta disimular, sin nada debajo y un pañuelo de flores en el escote» (Martín Gaite, 2010: 271) es el amigo de toda la vida, en el que siempre se puede confiar, un apoyo confortante, que nunca decepciona, que valoriza y alienta, válido para toda situación, una especie de amuleto passepartout.

Para las mujeres gaitianas el vestido representa incluso una máscara detrás de la que esconderse, como es el caso de Amparo Miranda. Para volver a sus orígenes en el intento de ordenar su vida -que transcurre en la frenética Nueva York- la famosa modista decide emprender un viaje a España, a los lugares de su juventud, abriendo la caja de Pandora de dolidos y nostálgicos recuerdos. Desde el momento en el que con su madre abandonó su tierra natal para cruzar el charco, Amparo crea e interpreta a un personaje: Miranda Drake, en efecto, esconde su identidad detrás de elegantes trajes y complementos a juego, protegida por la reciente cirugía estética y un seudónimo; todos elementos que no pertenecen a la cultura provinciana de su infancia. Pero solo de esta manera Amparo puede volver a su pueblo natal sin ser reconocida. Su ropa muy sofisticada y su aspecto de extranjera le permiten observar la realidad que había dejado hace cuarenta años sin ser descubierta. Como la mujer ventanera gaitiana por excelencia, Amparo es intérprete de sí misma, de la persona que había dejado de ser y, al mismo tiempo, voz de su renacimiento: «en una cosa coincidía su visión de entonces con la de ahora: en que procuraba ver sin ser vista» (Martín Gaite, 2008: 188). En esta novela

14 En el cuento de Baum las zapatillas son plateadas. 
la moda juega un papel fundamental: además de representar la actividad laboral de Amparo, marcando su cotidianidad, cuenta la gran pasión que la llevó a renunciar a todo lo que tenía, incluso a su gran amor Abel Bores -que la reconocerá gracias a una pulsera, complemento que identifica tanto a la joven Amparo como a la madura señora Drake-, para empezar una nueva vida en los Estados Unidos. Los trajes, en su caso, corresponden al medio para llegar a una real y total comprensión de sí, volviendo a su identidad, que en Nueva York se había hecho borrosa. Los tejidos, los hilos de colores, las máquinas de coser, el armario de luna y los maniquíes representan su pasado y su presente, el sentido de su auténtico ser, el elemento que une sus dos mundos, España y América. Son todos objetos de la memoria que comparte con su madre, mujer sólida y trabajadora, que durante los años más duros de la dictadura había tenido que soportar insinuaciones y juicios de la mentalidad provinciana y mojigata, encontrando en la difícil experiencia del exilio americano una auténtica bocanada de olvido, a pesar de las dificultades de abrazar una cultura totalmente nueva. Amparo y su madre, junto con las otras figuras femeninas de las que está plagada la novela -Társila, Manuela, Olimpia, Valeria, Alicia- representan el topos de la mujer fuerte, combativa y leal, cuya vida se entrelaza con las otras, al igual que la trama de un tapiz. El espejo es quizás el único fiel testigo de los cambios en las vidas de estas mujeres. Para Amparo además de revelar el desolador paso del tiempo y las imperturbables apariencias llega a ser un interlocutor a quien confesar pensamientos y angustias de un viaje al que incialmente no puede encontrar sentido, más allá que la huida de una ciudad que «la tenía atrapada» (Martín Gaite, 1998: 149).

A pesar del aspecto frívolo y superficial que se le atribuyó a lo largo de la historia, la moda es parte de nuestra cultura y del presente y, como tal, para Martín Gaite representa, junto a los ambientes domésticos, a las relaciones familiares, a la memoria y a la escritura, un elemento vital para completar y recrear fielmente aquel universo femenino al que dio voz durante medio siglo; un universo tan rico y vital, variado y heterogéneo como unido en la tentativa de deshacerse de un pasado muy difícil, que puede lograr también gracias al poder de la creación. 


\section{REFERENCIAS BIBLIOGRÁFICAS}

Agosín, Marjorie (1993), Las hacedoras: mujer, imagen, escritura, Santiago, Cuarto Propio.

Álvarez Vara, Ignacio (2005), «CMG con NYC de fondo», en Carmen Martín Gaite. Visión de Nueva York, Madrid, Siruela, págs. 125-130.

BARONCINI, Daniela (2010), La moda nella letteratura contemporanea, Milán, Mondadori.

BARTHES, Roland (1967), Système de la mode, París, Seuil, 2015.

Blanco López de Lerma, María José (2013), Life writing in Carmen Martín Gaite's "Cuadernos de todo" and her novels of the 1990s, Woodbrige, Tamesis.

CALVI, Maria Vittoria (2014), «Poética del lugar y actitud autobiográfica en Carmen Martín Gaite», en José Teruel Benavente y Carmen Valcárcel (eds.), Un lugar llamado Carmen Martín Gaite, Madrid, Siruela, págs. 124137.

Ciplijauskatté, Biruté (2000), Carmen Martín Gaite, Madrid, Del Orto.

COMETA, Michele (2004), Dizionario degli studi culturali, Milán, Booklet.

CONTADINI, Luigi (2000), «Esperienza e scrittura nella narrativa di Carmen Martín Gaite (a proposito di La Reina de las Nieves, Lo raro es vivir, Irse de casa)», en Rassegna iberistica, 70, págs. 13-21.

CRAIK, Jennifer (1993), The face of fashion. Cultural studies in fashion, Londres-Nueva York, Routledge.

CRANE, Diana (2000), Fashion and its social agendas: class, gender and identity in clothing, Chicago, University Press.

Cruz-Cámara, Nuria (2008), El laberinto intertextual de Carmen Martín Gaite. Un estudio de sus novelas de los Noventa, Newark, Juan de la Cuesta.

Eco, Umberto (1972), «L'abito parla il monaco», en Francesco Alberoni et al., Psicologia del vestire, Milán, Bompiani, págs. 7-25. 
ENCINAR, Ángeles y GLENN, Kathleen M. (2014), «Ventanas al yo y al mundo americano en los Cuadernos de todo, de Carmen Martín Gaite», en José Teruel Benavente y Carmen Valcárcel (eds.), Un lugar llamado Carmen Martín Gaite, Madrid, Siruela, págs. 94-108.

Escartín Gual, Montserrat (2001), «La palabra viva de Carmen Martín Gaite», en Ínsula, 649-650, págs. 36-38.

- (2014), «Carmen Martín Gaite: la escritura terapéutica», en Revista de Literatura, LXXVI, 152, págs. 575-603.

FREIXAS, Laura (2006), «Rosa Chacel, Carmen Martín Gaite: dos reflexiones en torno a mujer y creación», en Siglo XXI, literatura y cultura españolas: revista de la Cátedra Miguel Delibes, 4, págs. 47-58.

Gordon, Helen (2009), «Off the page: fashion in literature», en The Guardian, 19 de septiembre, https://www.theguardian.com/lifeandstyle/2009/ sep/19/fashion-in-literature.

Guy, Ali; Green, Eileen; BANIM, Maura (eds.) (2003), Through the wardrobe: women's relationships with their clothes, Oxford, Berg.

Jurado Morales, José (2003), La trayectoria narrativa de Carmen Martín Gaite (1925-2000), Madrid, Gredos.

Kawamura, Yuniya (2005), Fashion-ology. An introduction to Fashion Studies, Oxford-Nueva York, Berg.

Lipovetsky, Gilles (1987), L'Empire de l'éphémère. La mode et son destin dans les sociétés modernes, París, Gallimard.

López Alonso, Covadonga (2004), «El marco semántico de 'retahíla' como constructor del esquema narrativo», en Alicia Redondo Goicoechea (ed.), Carmen Martín Gaite, Madrid, Del Orto, págs. 135-147.

López Rodríguez, Irene (2011), «La costura como metáfora de construcción del modelo femenino en El cuarto de atrás», en Anuario brasileño de estudios hispánicos, 21, págs. 169-187.

LuRIE, Alison (1994), El lenguaje de la moda: una interpretación de las formas de vestir, Barcelona, Planeta. 
Martín Gaite, Carmen (1987), Usos amorosos de la postguerra española, Barcelona, Anagrama.

- (1993), «Bosquejo autobiográfico», en Id., Agua pasada. (Artículos, prólogos y discursos), Barcelona, Anagrama, 1993, págs. 1-25.

- (1997), El cuarto de atrás, Barcelona, Destino.

- (1998), Irse de casa, Barcelona, Anagrama.

- (1999), Desde la ventana, Madrid, Espasa Calpe.

- (2003), Cuadernos de todo, Barcelona, Random House Mondadori.

- (2005), Visión de Nueva York, Madrid, Siruela.

- (2010), Nubosidad variable, Barcelona, Anagrama.

Martinell Gifre, Emma (1996), El mundo de los objetos en la obra de Carmen Martín Gaite, Cáceres, UEX.

Medina, Hector (2009), «La dimensión autobiográfica de la obra de Carmen Martín Gaite», en María Mercedes González de Sandes (ed.), Donne, identità e progresso nelle culture mediterranee, Roma, Aracne, págs. 125-136.

MirAnda, Karen (2009), «El poder curativo de la palabra en Retahílas y El cuarto de atrás de Carmen Martín Gaite», en Ángeles Encinar y Carmen Valcárcel (eds.), Escritoras y compromiso: literatura española e hispanoamericana de los siglos XX y XXI, Madrid, Visor, págs. 493-500.

Montoya Ramírez, María Isabel (ed.) (2001), Las referencias estéticas de la moda. II Jornadas Internacionales sobre moda y sociedad, Granada, Universidad de Granada.

Redondo Goicochea, Alicia (2009), Mujeres y narrativa. Otra historia de la literatura, Madrid, Siglo XXI.

Widmann, Claudio (1999), Il simbolismo dei colori, Roma, Magi Edizioni.

Woolf, Virginia (1992), Orlando, Oxford, Oxford University Press.

ZECCHI, Barbara (2006), «Inconsciente genérico, feminismo y Nubosidad variable de Carmen Martín Gaite», en ARBOR Ciencia, Piensamento y Cultura, 720, págs. 527-535. 